\title{
Pharmaceutical stability of colloidal saccharated iron oxide injection in normal saline
}

\author{
Daiki Hira ${ }^{1,2}$, Asami Suzuki', Yusuke Kono ${ }^{3}$, Kosuke Shimokawa', Serika Matsuoka', Ken-yuh Hasumoto', \\ Hiroyuki Kawahara ${ }^{4}$, Masahide Onoue ${ }^{4}$, Takuya Fujita ${ }^{3}$, Tomonobu Okano ${ }^{1}$ and Mikio Kakumoto ${ }^{1 *}$
}

\begin{abstract}
Background: Colloidal saccharated iron oxide injection is used for the treatment of iron deficiency anemia in patients with a poor oral intake. Because of the poor stability of the colloid particle, there have been concerns regarding its compatibility with various injections in clinical practice. To assess the stability of colloidal saccharated iron oxide in normal saline as a diluent, pharmaceutical stability analyses were conducted using various concentrations of glucose and sodium chloride $(\mathrm{NaCl})$.

Methods: Colloidal saccharated iron oxide injection was diluted in three different diluents (5\% glucose solution, normal saline, and $10 \% \mathrm{NaCl}$ solution), and its appearance, colloid particle diameter, and pH were assessed. Free iron ions, which cause adverse effects, such as nausea and vomiting, were separated from the colloid particle using a dialysis membrane for $24 \mathrm{~h}$, and their concentration was determined.

Results: No difference in the appearance, colloid diameter, and free iron ion fraction was observed after dilution in 5\% glucose solution and normal saline. Conversely, an increased colloid aggregation and iron ion release were observed after dilution in $10 \% \mathrm{NaCl}$ solution. Although iron colloid is unstable in acidic conditions (pH 4.0-6.0), normal diluents such as $5 \%$ glucose and normal saline did not cause colloid destabilization by $\mathrm{pH}$ change $(\mathrm{pH}>8.0)$.

Conclusion: Normal saline may be used as a diluent of colloidal saccharated iron oxide injection as well as glucose solution, which is recommended by the pharmaceutical company. Therefore, normal saline can be used as a diluent of colloidal saccharated iron oxide injection in patients with an underlying disease, such as diabetes mellitus, who are difficult to use glucose solution as a diluent.
\end{abstract}

Keywords: Incompatibility, Colloid, Iron injection, Pharmaceutical stability, Electrolyte, Diluent

\section{Background}

Colloidal saccharated iron oxide injection is used for the treatment of iron deficiency anemia in patients with a poor oral intake [1-5]. Because of the colloid's stability, there have been concerns regarding its compatibility with various injections in clinical practice [6-8]. The disruption of the colloidal iron particle enhances the isolation of iron ions, resulting in adverse effects such as nausea and vomiting [9-11]. Therefore, the pharmaceutical company recommends the colloidal saccharated iron oxide (Fesin ${ }^{\circ}$ )

\footnotetext{
* Correspondence: mickeyka@fcritsumei.ac.jp

'Laboratory of Clinical Pharmacy, College of Pharmaceutical Sciences, Ritsumeikan University, 1-1-1 Noji-higashi, Kusatsu, Shiga 525-8577, Japan Full list of author information is available at the end of the article
}

to be diluted in glucose solution. Conversely, in clinical practice, using glucose solution as a diluent is difficult in patients with an underlying disease such as diabetes mellitus because additional glucose injection may cause a poor control of their disease. In such patients, normal saline $[0.9 \%$ sodium chloride $(\mathrm{NaCl})]$ has often been used as a diluent of colloidal saccharated iron oxide. Although electrolytes are well-known destabilizers of colloidal particles, normal saline is frequently used as a representative isotonic diluent. However, information regarding the pharmaceutical stability of colloidal saccharated iron oxide in various diluents, including normal saline but excluding glucose solution, has been lacking. In this study, the stability of colloidal saccharated iron oxide

(c) The Author(s). 2018 Open Access This article is distributed under the terms of the Creative Commons Attribution 4.0 International License (http://creativecommons.org/licenses/by/4.0/), which permits unrestricted use, distribution, and reproduction in any medium, provided you give appropriate credit to the original author(s) and the source, provide a link to the Creative Commons license, and indicate if changes were made. The Creative Commons Public Domain Dedication waiver (http://creativecommons.org/publicdomain/zero/1.0/) applies to the data made available in this article, unless otherwise stated. 
in normal saline as a diluent was assessed by conducting pharmaceutical stability analyses using various concentrations of glucose and $\mathrm{NaCl}$.

\section{Methods}

Fesin $^{\circ}$ (colloidal saccharated iron oxide for injection, 40 mg/2 mL; Nichi-Iko Pharmaceutical Co., Ltd., Toyama, Japan), glucose injection (5, 10, and 20\%; Otsuka Pharmaceutical Factory, Inc., Tokushima, Japan), and normal saline injection $(0.9 \% \mathrm{NaCl}$; Otsuka Pharmaceutical Factory, Inc., Tokushima, Japan) were purchased from the respective pharmaceutical companies. The other reagents and solvents, such as $\mathrm{NaCl}, 1,10$-phenanthroline, sulfuric acid, and hydroxylamine chloride were of analytical grade.

Influence of diluents on appearance and particle diameter The appearance of Fesin 1 A $(40 \mathrm{mg} / 2 \mathrm{~mL})$ in $50 \mathrm{~mL}$ of three different diluents ( $5 \%$ glucose solution, normal saline, and $1.25-10 \% \mathrm{NaCl}$ solution) was observed at 0 and $24 \mathrm{~h}$ after dilution. Although the pharmaceutical company recommends the use of a $10-20 \%$ glucose solution as a diluent in the Fesin ${ }^{\bullet}$ package, 5\% isotonic glucose solution is the standard diluent used for Fesin ${ }^{\circ}$ in clinical practice. Therefore, a $5 \%$ glucose solution was used as a control diluent. The diluted samples were stored at room temperature until assessment. Dilution conditions were set at frequently usage in clinical setting. The influence of $\mathrm{pH}$ change on its appearance was assessed between $\mathrm{pH} 4.0$ and 10.0, adjusted by the addition of $0.1 \mathrm{M}$ $\mathrm{HCl}$ after dilution with distilled water. To assess the participation of colloid particles, all samples were centrifuged for $2 \mathrm{~min}$ at $3500 \mathrm{rpm}(1100 \times \mathrm{g})$ before the assessment.

In addition to the evaluation of appearance, colloid particle diameters were determined at $0-24 \mathrm{~h}$ after dilution using various diluents (5\% glucose, normal saline, $1.25-10 \%$ $\mathrm{NaCl}$, and $\mathrm{pH} 4.0-10.0$ solutions) using dynamic light scattering analysis (Zetasizer nano ZS; Malvern Instruments, Ltd., Worcestershire, UK) at $25^{\circ} \mathrm{C}$.

\section{Influence of diluents on $\mathrm{pH}$ change}

$\mathrm{pH}$ changes were measured at $0-24 \mathrm{~h}$ after diluting Fesin $^{\circ} 1 \mathrm{~A}$ in $50 \mathrm{~mL}$ of three diluents (5\% glucose solution, normal saline, and $10 \% \mathrm{NaCl}$ solution). The diluted samples were stored at room temperature until measurement. The influence on $\mathrm{pH}$ was also assessed at various solute concentrations (glucose, $0-20 \% ; \mathrm{NaCl}, 0-10 \%$ ) and volumes $(10-50 \mathrm{~mL})$ of diluents at 0 and $24 \mathrm{~h}$ after dilution.

Free iron ion released from iron oxide colloid particles Free iron ions, which cause adverse effects such as nausea and vomiting [9-13], were separated from colloid particles (approximately $10 \mathrm{~nm}$ ) using dialysis membrane (Spectra Por ${ }^{\circ} 3.5 \mathrm{kDa}$; pore size, $<2 \mathrm{~nm}$; Spectrum, Inc.,
$\mathrm{OH}$, USA). One ampule of Fesin ${ }^{\circ}$ was diluted in $50 \mathrm{~mL}$ of three diluents (5\% glucose solution, normal saline, and $10 \% \mathrm{NaCl}$ solution) and used as the testing sample. Iron ions are adsorbed on the surface of the cellulose dialysis tube $[14,15]$; hence, to saturate the tube surface by iron ion adsorption, a certain concentration of the standard iron ion solution $(2 \mu \mathrm{g} / \mathrm{mL})$ was added to both the inside ( $2 \mathrm{~mL}$ testing sample solution) and outside (10 $\mathrm{mL}$ blank solution) of the dialysis tube (70 $\mathrm{mm} \times 11.5 \mathrm{~mm}$ i.d.). After stirring for $24 \mathrm{~h}$ at room temperature, the amount of free iron ions in the outside solution was determined using the colorimetric o-phenanthroline method [16]. Free iron ions derived from colloidal saccharated iron oxide were calculated from the difference in the outside iron ion concentrations between the sample and blank solutions. The calibration curve ranged from 0.16 to $10 \mu \mathrm{g} / \mathrm{mL}$. The colorimetric o-phenanthroline method is briefly summarized as follows: $25 \%$ sulfuric acid, $10 \mu \mathrm{L} ; 10 \%$ hydroxylamine chloride, $20 \mu \mathrm{L}$; acetate buffer, $40 \mu \mathrm{L}$; and $0.5 \%$ 1,10-phenanthroline, $40 \mu \mathrm{L}$ were added and mixed to $1 \mathrm{~mL}$ of sample solution collected from the outside of the dialysis tube [17]. After $15 \mathrm{~min}$ of incubation in dark at room temperature, the resultant compound is determined at $510 \mathrm{~nm}$.

\section{Statistical analysis}

Differences in each parameter among the three diluents were assessed using one-way analysis of variance (ANOVA) and Tukey's multiple comparisons $(P<0.05)$. All statistical analyses were performed using EZR (Saitama Medical Center, Jichi Medical University), which is a graphical user interface for $\mathrm{R}$ (the $\mathrm{R}$ Foundation for Statistical Computing, version 3.3.2) [18].

\section{Results}

Influence of diluents on particle appearance and diameter Figure 1 shows the change of appearance at 0 and $24 \mathrm{~h}$ after dilution in three diluents (5\% glucose, normal saline, and $10 \% \mathrm{NaCl})$. There was no obvious difference in $5 \%$ glucose and normal saline at both time points. Conversely, dilution in 2.5 and $5 \% \mathrm{NaCl}$ caused a slight precipitation at $24 \mathrm{~h}$; furthermore, dilution in $10 \% \mathrm{NaCl}$ resulted in a suspension at $0 \mathrm{~h}$ and a drastic precipitation at $24 \mathrm{~h}$. The similar results were observed in particle diameter (Fig. 2). Significantly larger particles were detected in dilution with $10 \% \mathrm{NaCl}$, whereas colloid diameters in $5 \%$ glucose and normal saline were $10-15 \mathrm{~nm}$ at $24 \mathrm{~h}$ after dilution.

\section{Influence of diluents on $\mathrm{pH}$ change}

Figure $3 \mathrm{a}$ shows $\mathrm{pH}$ change after dilution. There were no time-dependent trends of $\mathrm{pH}$ change in all diluents, while $\mathrm{pH}$ in all diluents decreased from $\mathrm{pH}$ 9.0-9.7 to $\mathrm{pH}$ 8.5-9.3 after dilution. The influence of solute 


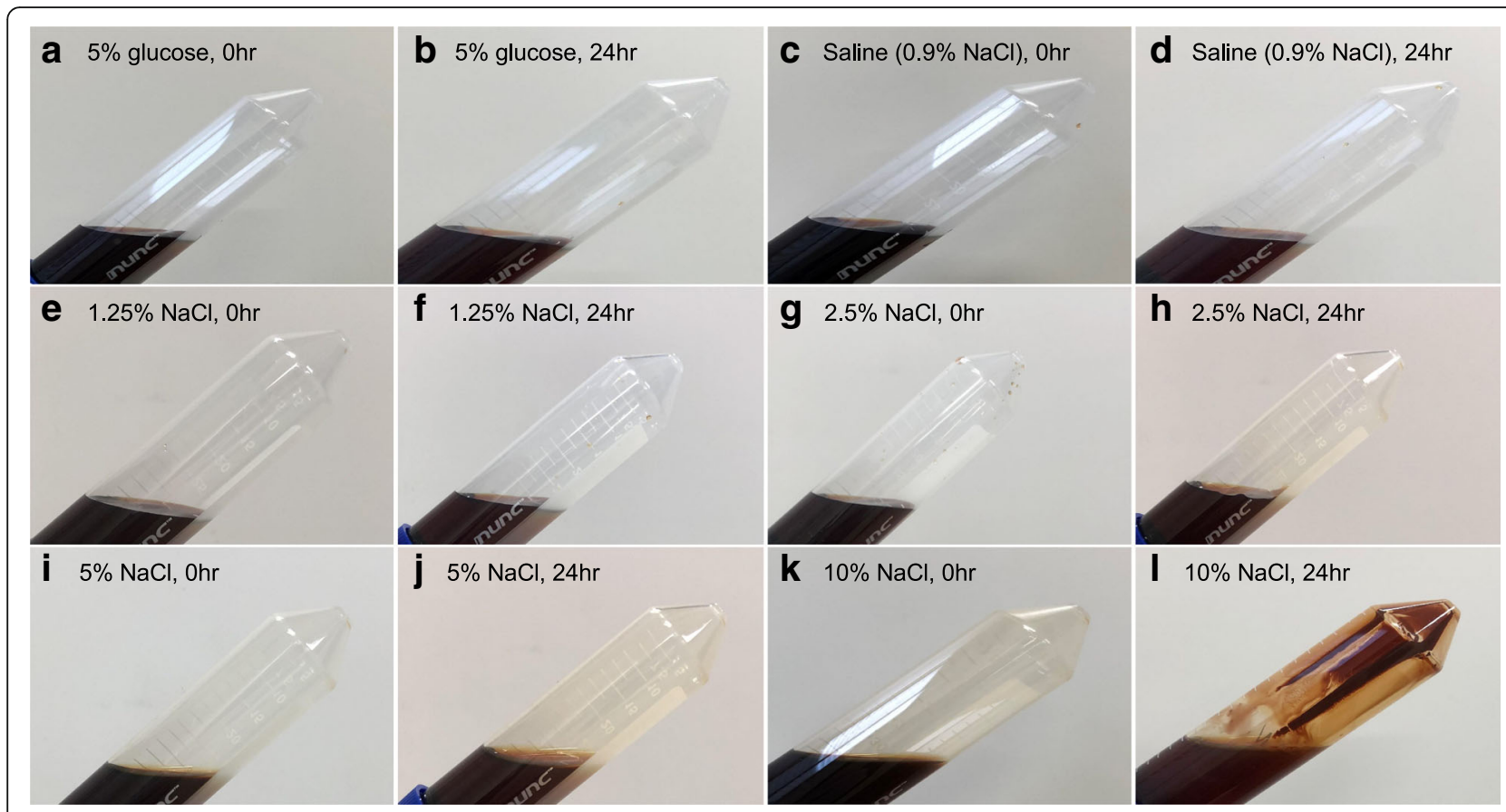

Fig. 1 Time-dependent appearance change of colloidal saccharated iron oxide in three different diluents. 5\% glucose solution (a, b), normal saline $(0.9 \% \mathrm{NaCl}$ solution) $(\mathbf{c}, \mathbf{d}), 1.25 \%(\mathbf{e}, \mathbf{f}), 2.5 \%(\mathbf{g}, \mathbf{h}), 5 \%(\mathbf{i}, \mathbf{j})$, and $10 \%(\mathbf{k}, \mathbf{l}) \mathrm{NaCl}$ solution at $0(\mathbf{a}, \mathbf{c}, \mathbf{e}, \mathbf{g}, \mathbf{i}, \mathbf{k})$ and $24(\mathbf{b}, \mathbf{d}, \mathbf{f}, \mathbf{h}, \mathbf{j}, \mathbf{I}, \mathbf{h})$

concentration and volume of diluents were also investigated (Fig. 3bc). A higher solute concentration and larger volume of diluent resulted in lower $\mathrm{pH}$; however, the lowest $\mathrm{pH}$ in the testing conditions was $\mathrm{pH}$ 8.0. Regarding the colloid appearance, iron colloid was unstable in acidic conditions ( $\mathrm{pH}$ 4.0-6.0; Fig. 3d-g). Figure 4 reports colloid particle median diameters at different $\mathrm{pH}$ levels and appearance change. Significantly larger particles were detected at $\mathrm{pH} 4.0$, whereas colloid particle diameters at $\mathrm{pH}$ 6.0-10.0 were between 10 and $20 \mathrm{~nm}$ at $24 \mathrm{~h}$ after dilution.

\section{Free iron ions released from iron oxide colloid particles} Figure 5 demonstrates the amount of free iron ions released from iron oxide colloid particles in the three tested diluents. $10 \% \mathrm{NaCl}$ produced a two-fold greater free iron ion isolation ratio than $5 \%$ glucose and normal
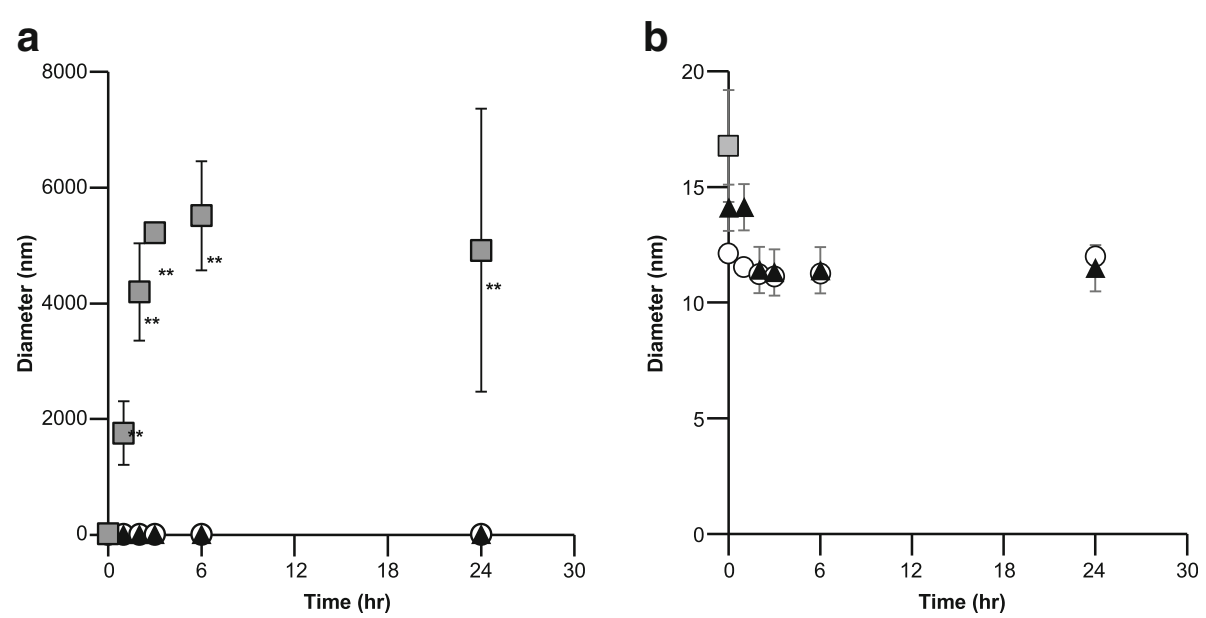

Fig. 2 Colloid particle diameter after dilution by various diluents. b An enlarged view of (a) gray squares, $10 \% \mathrm{NaCl}$ solution; black triangles, normal saline (0.9\% NaCl solution); and white circles, $5 \%$ glucose solution. ${ }^{* *} P<0.01$ vs. $5 \%$ glucose and normal saline (ANOVA with Tukey's test) 
a

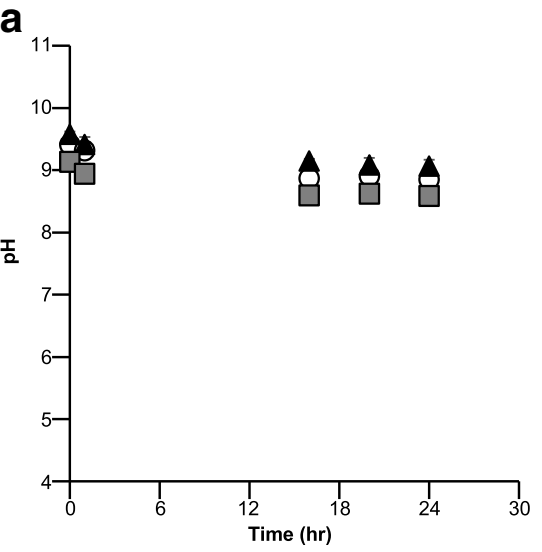

C

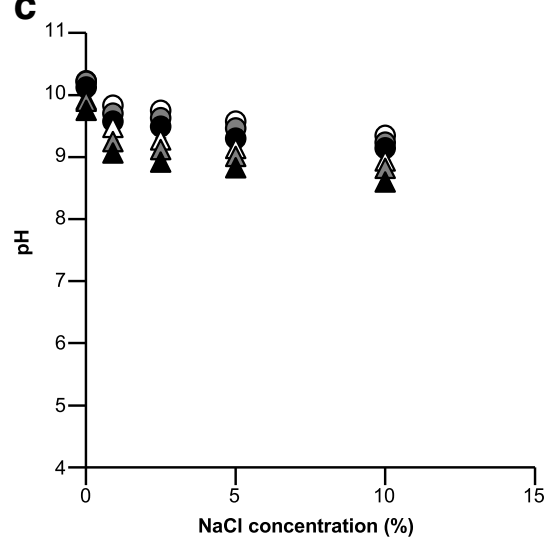

b
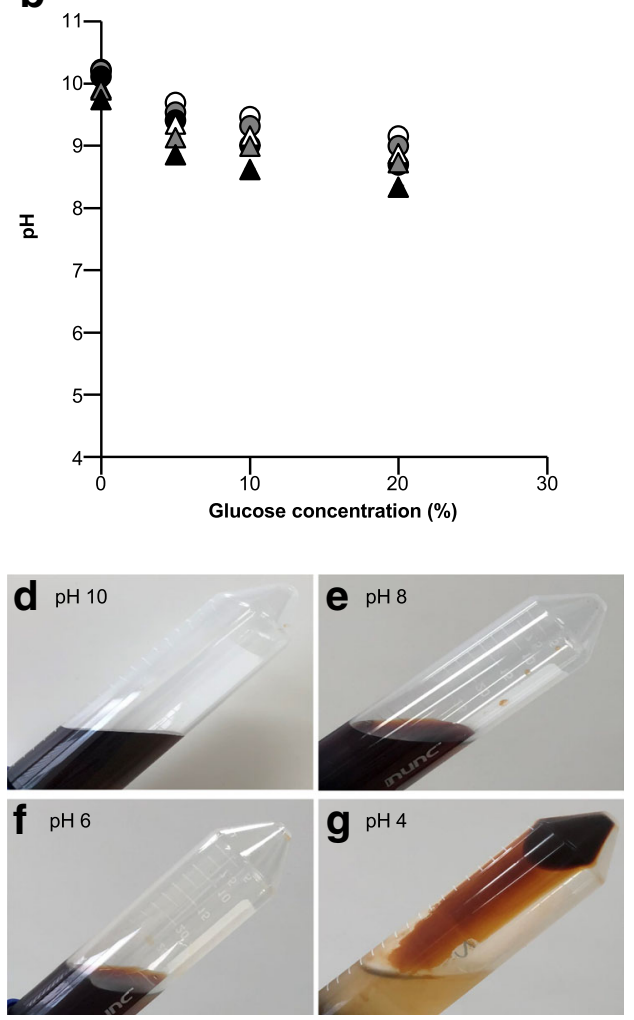

Fig. 3 a Time-dependent $\mathrm{pH}$ change in various diluents. Gray squares, $10 \% \mathrm{NaCl}$; black triangles, normal saline; and white circles, $5 \%$ glucose. b, c Relationship between $\mathrm{pH}$ and solute concentration in different diluents. Volumes of diluents are represented by different colors. White, gray, and black plots indicate $10 \mathrm{~mL}, 20 \mathrm{~mL}$, and $50 \mathrm{~mL}$, respectively. Circles and triangles indicate 0 and $24 \mathrm{~h}$ after dilution, respectively. $\mathbf{d}-\mathbf{g}$ Colloid stability in different $\mathrm{pH}$ conditions
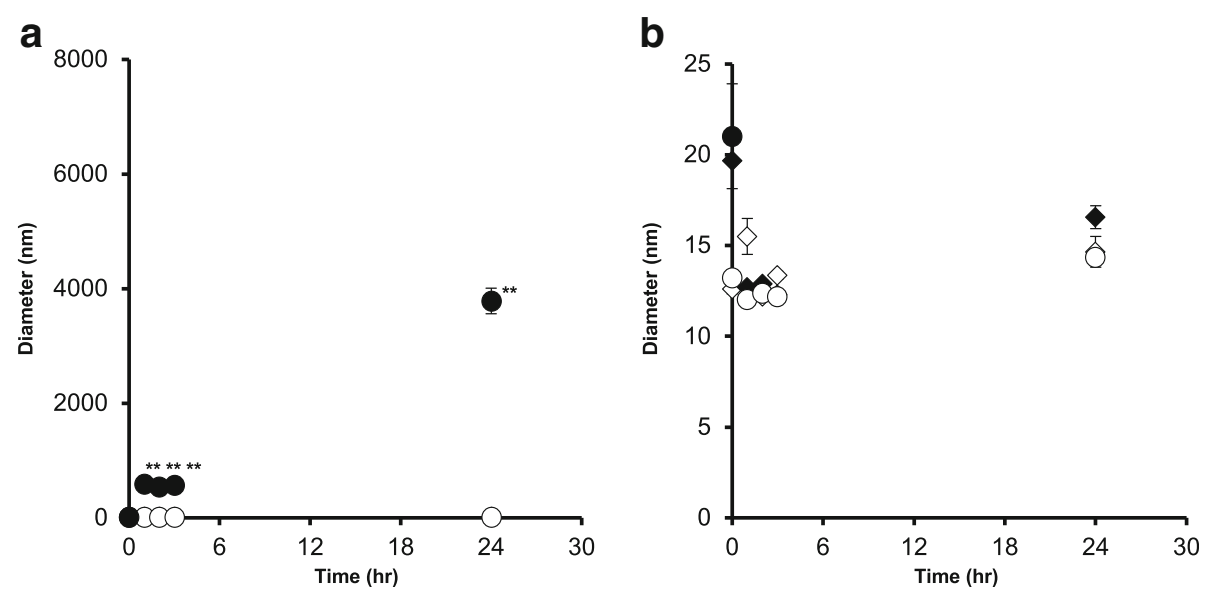

Fig. 4 Colloid particle diameters after dilution at different pH levels. b An enlarged view of (a) black circles, pH 4.0; white circles, pH 6.0; black triangles, $\mathrm{pH} 8.0$; and white triangles, $\mathrm{pH} 10.0$. ${ }^{* *} \mathrm{P}<0.01 \mathrm{vs}$. pH 6.0-10.0 (ANOVA with Tukey's test) 


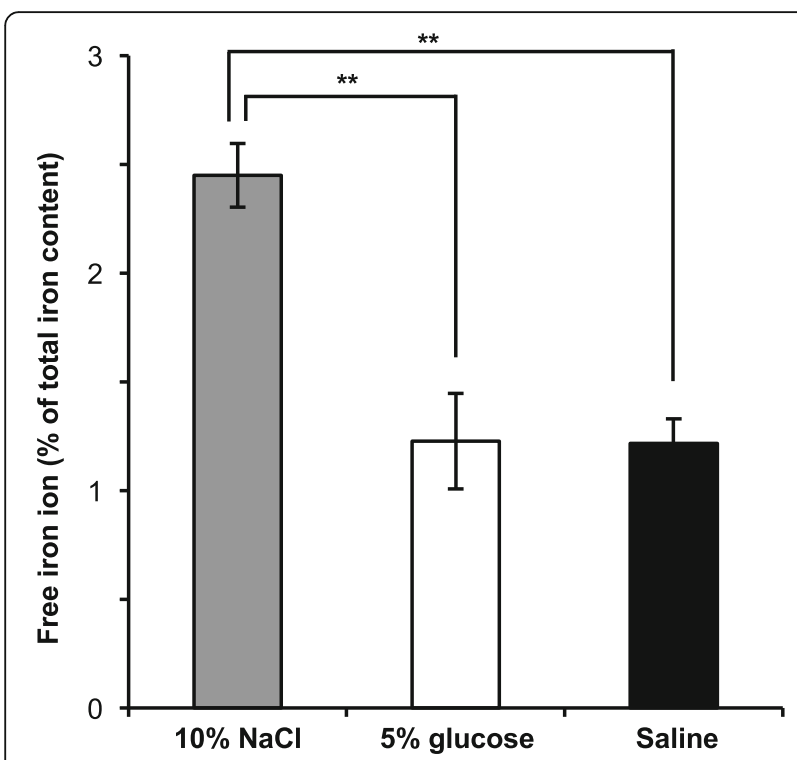

Fig. 5 Amount of free iron ions released from iron colloid particles at $24 \mathrm{~h}$ after dilution. Data are presented as mean $\pm \mathrm{SD}(n=3)$. ${ }^{* *} P<$ 0.01 vs. $5 \%$ glucose and normal saline (ANOVA with Tukey's test)

saline. Conversely, there was no difference between $5 \%$ glucose and normal saline.

\section{Discussion}

In this study, we investigated the pharmaceutical stability of a colloidal saccharated iron oxide injection in normal saline. The results of appearance, particle diameter, and free iron ion detection tests suggested no significant difference in the pharmaceutical stability between $5 \%$ glucose and normal saline, except for $10 \% \mathrm{NaCl}$. The destabilization of iron colloid caused by the higher amount of electrolyte derived from $10 \% \mathrm{NaCl}$ leads to the aggregation and enlargement of colloidal particles and in a higher ratio of free iron ion release. From a therapeutic viewpoint, $\mathrm{pH}$ and electrolyte levels at the site of colloid administration are important concerns, because of their effects on the surface potential of the colloid particles, which determines the colloid stability [6]. In the Fesin $^{\oplus}$ package insert information, the pharmaceutical company also calls the attention of medical professionals to these drug interactions. Herein, $\mathrm{pH}$ test revealed that the colloid appearance and diameter were stable between pH 8.0-10.0; however, they were unstable under acidic conditions ( $\mathrm{pH} 4.0-6.0$ ). Therefore, in the clinical setting, normal diluents such as $5 \%$ glucose and normal saline do not cause colloid destabilization by $\mathrm{pH}$ change $(\mathrm{pH}>$ 8.0 in clinical condition). Conversely, electrolytes are well-known destabilizers of colloidal particles $[6,19,20]$. $\mathrm{NaCl}$ is a typical electrolyte, which may cause colloid destabilization; however, low $\mathrm{NaCl}$ concentration, such as in normal saline $(0.9 \%)$, may not cause the destabilization. Hence, a high $\mathrm{NaCl}$ concentration $(2.5-10 \%)$ is necessary to decrease the stability of colloidal iron injection. From the viewpoint of clinical usage, there is no pharmaceutical destabilization of colloidal saccharated iron oxide at low $\mathrm{NaCl}$ concentrations (such as normal saline, 0.9\%). Normal saline should be a suitable diluent for colloidal saccharated iron oxide in patients with diabetes mellitus. Thermal conditions are critical in evaluating colloid stability. Shah et al. reported that there was no change in the molecular weight of iron colloid after heating at $30{ }^{\circ} \mathrm{C}$ and $40{ }^{\circ} \mathrm{C}$ for 35 days. However, the iron colloid destabilized when heated at $50{ }^{\circ} \mathrm{C}$ and $70{ }^{\circ} \mathrm{C}$ post 7 days [6]. Based on these information, room temperature is more severe condition than cool condition $\left(4{ }^{\circ} \mathrm{C}\right)$. Therefore, in our study, the assessment of stability at room temperature can be considered robust according to common clinical conditions. A limitation of our study is that no clinical data were available to assess the safety and efficacy of normal saline as a diluent of colloidal saccharated iron oxide. Further clinical study should be conducted to address this concern.

\section{Conclusion}

This study suggests that normal saline can be used as diluents of colloidal saccharated iron oxide as well as glucose solution, which is recommended by the pharmaceutical company. In clinical practice, glucose solution is difficult for use as a diluent in patients with an underlying disease such as diabetes mellitus. In such patients, normal saline is advantageous to decrease the risk of poor diabetes mellitus control. Although further clinical study should be conducted to demonstrate its safety and efficacy, this is the first useful information about the diluent selection for colloidal saccharated iron oxide injection.

\section{Acknowledgments}

We are grateful to Professor Mitsuru Hashida (Kyoto University, Japan) for providing the apparatus to measure particle diameter.

Funding

This work was supported in part by JSPS KAKENHI (grant number: 17 K15504).

Availability of data and materials

All data analysed during this study are included in this published article.

\section{Authors' contributions}

$\mathrm{DH}, \mathrm{HK}, \mathrm{MO}, \mathrm{TO}$, and MK contributed to the study conception and design. DH, $\mathrm{AS}, \mathrm{YK}, \mathrm{KS}$, and SM were involved in collection and analysis of data. DH drafted the manuscript, and $\mathrm{YK}, \mathrm{KH}, \mathrm{TF}, \mathrm{TO}$, and MK critically revised the manuscript. All authors read and approved the final manuscript.

\section{Competing interest}

The authors declare that they have no competing interests.

Ethics approval and consent to participate Not applicable.

Consent for publication

Not applicable. 


\section{Publisher's Note}

Springer Nature remains neutral with regard to jurisdictional claims in published maps and institutional affiliations.

\section{Author details}

'Laboratory of Clinical Pharmacy, College of Pharmaceutical Sciences, Ritsumeikan University, 1-1-1 Noji-higashi, Kusatsu, Shiga 525-8577, Japan. ${ }^{2}$ Department of Pharmacy, Shiga University of Medical Science Hospital, Seta Tsukinowa-Cho, Otsu, Shiga 520-2192, Japan. 'Laboratory of Molecular Pharmacokinetics, College of Pharmaceutical Sciences, Ritsumeikan University, 1-1-1 Noji-higashi, Kusatsu, Shiga 525-8577, Japan. ${ }^{4}$ Department of Pharmacy, Kitano Hospital The Tazuke Kofukai Medical Research Institute, 2-4-20 Ohgimachi, Kita-ku, Osaka 530-8480, Japan.

Received: 6 April 2018 Accepted: 28 June 2018

Published online: 25 July 2018

\section{References}

1. Onken JE, Bregman DB, Harrington RA, Morris D, Acs P, Akright B, Barish C, Bhaskar BS, Smith-Nguyen GN, Butcher A, et al. A multicenter, randomized, active-controlled study to investigate the efficacy and safety of intravenous ferric carboxymaltose in patients with iron deficiency anemia. Transfusion (Paris). 2014;54:306-15

2. Araki T, Takaai M, Miyazaki A, Ohshima S, Shibamiya T, Nakamura T, Yamamoto K. Clinical efficacy of two forms of intravenous iron-saccharated ferric oxide and cideferron-for iron deficiency anemia. Pharmazie. 2012;67:1030-2.

3. Auerbach M. Intravenous iron in chemotherapy-induced anemia. Am J Hematol. 2014:89:1153.

4. Bhandari S, Kalra PA, Kothari J, Ambühl PM, Christensen JH, Essaian AM, Thomsen LL, Macdougall IC, Coyne DW. A randomized, open-label trial of iron isomaltoside 1000 (Monofer $^{\oplus}$ ) compared with iron sucrose (Venofer ${ }^{\oplus}$ ) as maintenance therapy in haemodialysis patients. Nephrol Dial Transplant. 2015;30:1577-89

5. Fishbane $\mathrm{S}$, Kowalski EA. The comparative safety of intravenous iron dextran, iron saccharate, and sodium ferric gluconate. Semin Dial. 2000;13:381-4.

6. Shah RB, Yang Y, Khan MA, Raw A, Yu LX, Faustino PJ. Pharmaceutical characterization and thermodynamic stability assessment of a colloidal iron drug product: iron sucrose. Int J Pharm. 2014;464:46-52.

7. Dillon R, Momoh I, Francis Y, Cameron L, Harrison CN, Radia D. Comparative efficacy of three forms of parenteral iron. J Blood Transfus. 2012;2012:473514.

8. Zolezzi M. Intravenous Iron Saccharate complex: guidelines for its use in the Management of Anemia of renal disease. Saudi J Kidney Dis Transpl. 2003;14:129-33.

9. Hayat A. Safety issues with intravenous iron products in the management of anemia in chronic kidney disease. Clin Med Res. 2008;6:93-102.

10. Auerbach M, Al Talib K. Low-molecular weight iron dextran and iron sucrose have similar comparative safety profiles in chronic kidney disease. Kidney Int. 2008;73:528-30

11. Giannoulis C, Daniilidis A, Tantanasis T, Dinas K, Tzafettas J. Intravenous administration of iron sucrose for treating anemia in postpartum women. Hippokratia. 2009;13:38-40.

12. Danielson BG. Structure, chemistry, and pharmacokinetics of intravenous iron agents. J Am Soc Nephrol. 2004:15(Suppl 2):S93-8.

13. Heath CW, Strauss MB, Castle WB. QUANTITATIVE ASPECTS OF IRON DEFICIENCY IN HYPOCHROMIC ANEMIA: (The Parenteral Administration of Iron). J Clin Invest. 1932;11:1293-312.

14. LICH W, Schweizer T, Asp N. Minerals and phytate in the analysis of dietary fiber from cereals. II. Cereal Chem. 1984;61:357-9.

15. Leigh MJ, Miller DD. Effects of $\mathrm{pH}$ and chelating agents on iron binding by dietary fiber: implications for iron availability. Am J Clin Nutr. 1983;38:202-13.

16. Saywell L, Cunningham B. Determination of iron: colorimetric o-phenanthroline method. Ind Eng Chem Anal Ed. 1937:9:67-9.

17. Gupta UC. Studies on the o-phenanthroline method for determining iron in plant materials. Plant Soil. 1968:28:298-305.

18. Kanda Y. Investigation of the freely available easy-to-use software 'EZR' for medical statistics. Bone Marrow Transplant. 2013:48:452-8.

19. Yang Y, Shah RB, Faustino PJ, Raw A, Yu LX, Khan MA. Thermodynamic stability assessment of a colloidal iron drug product: sodium ferric gluconate. J Pharm Sci. 2010;99:142-53.
20. Shah RB, Yang Y, Khan MA, Faustino PJ. Molecular weight determination for colloidal iron by Taguchi optimized validated gel permeation chromatography. Int J Pharm. 2008;353:21-7.

\section{Ready to submit your research? Choose BMC and benefit from:}

- fast, convenient online submission

- thorough peer review by experienced researchers in your field

- rapid publication on acceptance

- support for research data, including large and complex data types

- gold Open Access which fosters wider collaboration and increased citations

- maximum visibility for your research: over $100 \mathrm{M}$ website views per year

At BMC, research is always in progress.

Learn more biomedcentral.com/submissions 